\title{
Biocultural Diversity Conservation: A Global Sourcebook
}

Luisa Maffi and Ellen Woodley. 2010. Earthscan, London. Pp. 304. \$57.95 (paperback). ISBN 978-1-84407-921-6.

Reviewed by Jose Martinez-Reyes

Reviewer Address: Department of Anthropology, University of Massachusetts, Boston, MA 02125

Received: February 1, 2012

Volume 3:61-62

Published: September 26, 2012

(C)2012 Society of Ethnobiology

Conservation of natural resources has increasingly been on the agendas of many governments, global institutions, environmentalists, scholars, and the public in general in recent decades. The focus of conservation, particularly in the tropics, has been overwhelmingly towards biological diversity, or biodiversity. It is precisely this unbalance that Maffi and Woodley seek to address in 'Biocultural Diversity Conservation: A Global Sourcebook.' They argue that this emphasis on the biological aspects has relegated people, mostly indigenous groups that have interacted with these resources and in many cases have contributed to protecting and regenerating biological diversity, to a symbolic place. By this I mean that this book seeks to rectify the subordinated role that culture and traditional environmental knowledge have played in the world of conservation.

This book builds on previous work to confront the problems faced by human populations that have close and interdependent relations with their environments. Maffi and Woodley have been pioneers in the field, and in many ways this "sourcebook" makes the case for making biocultural research more visible, if not more mainstream, in conservation circles. The book is divided into three sections. The first section has two chapters that focus on the theoretical framework of biocultural diversity. The second section consists of four chapters that engage the readers with examples of projects that integrate biocultural diversity as their core for conservation initiatives. The last part contains two chapters that focus on tying together the loose ends and making sense of the dozens of case studies presented.

Their objectives- "to connect the dots" between several life projects with similar objectives, to link biocultural conservation projects, to increase public visibility, to create a larger united front-are not only commendable, but more importantly, are urgent.
There are projects and NGOs, in my experience, that emphasize or claim that they are working with indigenous groups to protect their traditional ecological knowledge, but in reality are only paying lip service and, to the contrary, want to implement a Western scientific rationality over traditional ecological knowledge. I do not intend to imply that the case studies presented in this book fall into that category, but it is something that readers should be aware of.

From the outset, the authors warn readers about what precisely I thought where the shortcomings: that the surveys are not systematic enough to elaborate on the conflicts or difficulties that occur as a consequence of the interactions between different groups. That probably would be the task of a more in-depth ethnographic analysis. There was a mix of contributors. Among them were anthropologists, NGO personnel, and indigenous people. The case studies work well to contextualize the biocultural elements of each community as they provide vivid descriptions of the landscape and the conservation projects. Some anthropologists, however, would like to know more of the intimate details about the dynamics between conservation projects and indigenous peoples, principally the contentious issues that surround particular Western notions of conservation versus local indigenous point of views.

The task of promoting biocultural diversity is immense and, I dare to say, urgent as the threat of loss of languages and connections to land seems to grow as time goes by. This book shows the ways in which it is possible to reverse this trend. Connecting local experiences and indigenous groups with each other can reaffirm that, by defending their connection to their land, their language, and by continuing their engagement with their environment, indigenous people are contributing, not only to their 'life projects', but to global diversity as well. In spite of the shortcomings 
that the authors themselves point out, this book is a compelling case for reconceptualising conservation through the biocultural perspective. The book should be indispensible for NGOs, grassroots organizations, and scholars that intend to, or already works with, the complex connections between indigenous populations and conservation. 